http://dx.doi.org/10.22319/rmcp.v10i1.4350

Nota de investigación

\title{
Impacto de la vigilancia sanitaria del clembuterol en Guerrero, México:
}

Resultados de 2011 a 2015

Luis Alberto Chávez-Almazánª*

Jesús Antonio Díaz-Ortiz ${ }^{\text {b }}$

Diana Garibo-Ruiz ${ }^{\mathrm{c}}$

Mario Alberto Alarcón-Romero ${ }^{\mathrm{b}}$

Miguel Angel Mata-Diaz ${ }^{\mathrm{b}}$

Beatriz Pérez-Cruz

Elizabeth Godoy-Galeana ${ }^{\mathrm{b}}$

${ }^{a}$ Universidad Autónoma de Guerrero. Facultad de Ciencias Químico Biológicas. Guerrero, México.

b Secretaría de Salud de Guerrero. Laboratorio Estatal de Salud Pública “Dr. Galo Soberón y Parra”. Guerrero, México.

${ }^{c}$ Centro de Investigación Científica y de Educación Superior de Ensenada, Baja California. México.

*Autor de correspondencia: chavez_79@ hotmail.com>

\section{Resumen:}

El empleo del clembuterol en la producción de ganado implica riesgos a la salud humana que deben ser evaluados y atendidos por las autoridades agropecuarias y sanitarias. En este trabajo se evaluaron los resultados del programa de vigilancia sanitaria de dicho compuesto en productos cárnicos de bovinos que se comercializan en Guerrero, México. Se realizó un 
análisis retrospectivo del periodo comprendido entre 2011 y 2015, sobre la evolución de su uso ilegal y el registro de intoxicaciones alimentarias por clembuterol. Los porcentajes de muestras positivas disminuyeron gradualmente hasta quedar en 2015 en $6.8 \%$ y, en general, fueron más bajos en comparación con los antecedentes inmediatos; sin embargo, siempre fueron superiores a los porcentajes promedio del resto del país (Guerrero= $9.5 \%$, Nacional= $5.8 \%$ ). Las jurisdicciones sanitarias con mayor presencia del fármaco fueron Tierra Caliente y Norte, con 12.1 y $16.8 \%$, respectivamente, así como en lugares con una población grande como Acapulco $(9.6 \%)$. Se reportaron pocos casos de intoxicaciones humanas en los tres primeros años $(2011=3,2012=5$ y $2013=4)$ y ninguno en los dos posteriores; sin embargo, hay un sub-registro que puede deberse a diversos factores tanto individuales, regionales e institucionales que se discuten más adelante. El avance observado en este programa ha sido significativo; sin embargo, debe fortalecerse la vigilancia sanitaria con la finalidad de erradicar esta actividad ilegal en el corto plazo.

Palabras clave: Clembuterol, Intoxicación alimentaria, Vigilancia sanitaria.

Recibido: 14/01/2017

Aceptado: 29/11/2017

El clembuterol es un compuesto agonista de los receptores beta-adrenérgicos del músculo liso vascular, miometrial y bronquial, utilizado en la medicina veterinaria como broncodilatador y tocolítico $^{(1)}$, y en algunos países está autorizado para su administración en el tratamiento de enfermedades respiratorias en humanos. Debido a que actúa como agente de repartición en animales mediante la eliminación de grasas y promoviendo la síntesis de proteínas, se provoca un acelerado crecimiento de la masa muscular, por lo cual este compuesto se utiliza de manera ilegal e indiscriminada con fines de producción cárnica de ganado bovino $^{(2-5)}$. La ingesta de alimentos con residuos de clembuterol representa un riesgo para el consumidor, dado que puede derivar en graves intoxicaciones que se asocian con síntomas como palpitaciones, taquicardia, cefalea, temblor en extremidades, presión arterial elevada, ansiedad, nerviosismo, prurito, náuseas, dolor estomacal, fiebre, vómito, astenia y debilidad muscular, los cuales están acompañados de alteraciones de algunos parámetros hematológicos (leucocitosis) y bioquímicos, como electrolitos y glucosa ${ }^{(6-10)}$.

Con la finalidad de proteger a la población contra el riesgo por el consumo de alimentos contaminados por clembuterol, la Subsecretaría de Regulación, Control y Fomento 
Sanitario, dependiente de la Secretaría de Salud del Estado de Guerrero, ha implementado el Programa de Inocuidad Alimentaria (antes denominado Proyecto de Alimentos Potencialmente Peligrosos) desde el año 2005 basándose en la Norma Oficial Mexicana NOM-194-SSA1-2004 ${ }^{(11)}$, que consta de visitas de verificación en diversos establecimientos como mercados, rastros y tiendas de autoservicio, en las cuales se recolectan muestras de productos cárnicos para la detección de clembuterol por el Laboratorio Estatal de Salud Pública de Guerrero "Dr. Galo Soberón y Parra" (LESP-Guerrero) basado en el inmunoensayo enzimático Ridascreen Clenbuterol Fast (r-biopharm, Alemania) ${ }^{(12)}$. Este trabajo tuvo como finalidad evaluar los resultados de este programa para determinar su efectividad en la reducción del uso ilegal del clembuterol en la producción de ganado bovino para su consumo en el estado de Guerrero.

El estudio se realizó de manera retrospectiva, transversal, observacional y comparativa. Se llevó a cabo un análisis de los resultados del programa de vigilancia sanitaria del clembuterol en Guerrero implementado entre los años 2011 a 2015, para determinar la idoneidad del esquema de muestreo y establecer si existió una tendencia en los porcentajes de casos positivos a través de los años, además de la comparación entre los resultados obtenidos con respecto a la situación a nivel nacional. También, se aplicó un análisis regional y municipal del comportamiento del uso del clembuterol, así como un recuento de las intoxicaciones alimentarias derivadas de esta práctica ilegal.

De los establecimientos visitados por los verificadores sanitarios, se recolectaron muestras de hígado y músculo de bovinos, aproximadamente $250 \mathrm{~g}$ (de manera ocasional, se tomaron muestras de globo ocular y orina), para la detección de clembuterol. Las muestras se almacenaron en bolsas de polietileno y frascos de plástico con tapa de rosca (para muestras de orina), perfectamente identificadas y transportadas al LESP-Guerrero a una temperatura entre 2 y $8^{\circ} \mathrm{C}$. La preparación de las muestras se realizó de la siguiente manera:

A) Hígado y músculo. Se depositaron $5 \mathrm{~g}$ de la muestra previamente triturada en un tubo para centrífuga de $50 \mathrm{ml}$ (Corning, Estados Unidos de América), luego se agregaron $25 \mathrm{ml}$ de $\mathrm{HCl}$ $0.05 \mathrm{M}$ y se agitó mecánicamente por $20 \mathrm{~min}$; posteriormente se centrifugó a 4,000 xg durante $15 \mathrm{~min}$ a una temperatura entre 10 y $15^{\circ} \mathrm{C}$, y se transfirieron $18 \mathrm{ml}$ de sobrenadante a otro tubo, al cual se le agregaron $2 \mathrm{ml}$ de $\mathrm{NaOH} 0.5 \mathrm{M}$ y se mezcló por 10 min. Finalmente, se adicionaron $4 \mathrm{ml}$ de buffer de fosfatos $\left(\mathrm{KH}_{2} \mathrm{PO}_{4} 0.5 \mathrm{M} \mathrm{pH} 3\right)$ y se homogenizó para dejarlo reposar otros 90 min a $2-8{ }^{\circ} \mathrm{C}$; posteriormente, se centrifugó y se tomaron $10 \mathrm{ml}$ de sobrenadante y se pasaron a través de columnas de extracción en fase sólida tipo C18 (rbiopharm, Alemania).

B) Globo ocular. Las piezas se congelaron a $-20^{\circ} \mathrm{C}$ durante $24 \mathrm{~h}$ para lisar el tejido. Después, se realizó la disección y el líquido obtenido se diluyó con agua destilada en una relación 1:2 y se centrifugó a 2,000 xg durante 5 min. Del sobrenadante se tomaron $20 \mu \mathrm{l}$ para el inmunoensayo. 
C) Orina. Estas muestras se analizaron directamente sin un tratamiento previo de extracción, y solamente cuando presentaron turbiedad se centrifugaron a 2,000 xg durante $5 \mathrm{~min}$. El volumen adecuado para el análisis fue de 30 a $50 \mathrm{ml}$.

La extracción en fase sólida se llevó a cabo acondicionando la columna C18 con $3 \mathrm{ml}$ de metanol y se agregaron $2 \mathrm{ml}$ de un buffer de enjuague $\left(\mathrm{KH}_{2} \mathrm{PO}_{4} 0.05 \mathrm{M} \mathrm{pH} 3\right)$; se aplicó el sobrenadante y se agregaron $3 \mathrm{ml}$ de buffer de enjuague; la columna se secó y eluyó lentamente con $1 \mathrm{ml}$ de metanol grado HPLC (Honeywell Burdick and Jackson, Estados Unidos de América); la concentración del extracto se realizó a 50 a $60{ }^{\circ} \mathrm{C}$ bajo una corriente de aire; el residuo seco se reconstituyó con $400 \mu \mathrm{l}$ de agua grado HPLC (Sigma Aldrich, Suiza).

El análisis de los extractos se realizó por medio de un inmunoensayo enzimático competitivo (Ridascreen Clembuterol Fast, r-biopharm, Alemania) ${ }^{(12)}$ con lectura en un espectrofotómetro UV-Vis iMark (Bio-Rad Laboratories Inc, Estados Unidos de América) a $450 \mathrm{~nm}$; la concentración de clembuterol se expresó en ng/kg o ppt (partes por trillón). De conformidad con la NOM-194-SSA1-2004(11), se consideraron como muestras contaminadas, detectadas o positivas, aquéllas que presentaron concentraciones mayores a 2,000 ng/kg; las muestras con resultados inferiores se interpretaron como no detectadas con clembuterol. Sobre la calidad analítica del método, se cumplieron los criterios de aceptación descritos en el inserto del reactivo ${ }^{(12)}$; asimismo, en cada corrida se analizaron controles comerciales y muestras con concentraciones conocidas, obteniendo siempre los valores esperados. Cabe mencionar que este Laboratorio está facultado por la Comisión Federal para la Protección contra Riesgos Sanitarios (COFEPRIS) como Tercero Autorizado para la realización de pruebas analíticas en materia de regulación y control sanitario con base al cumplimiento de los requisitos técnicos y de gestión de calidad establecidos en la NMX-EC-17025-IMNC$2006^{(13)}$.

Se analizaron estadísticamente los resultados obtenidos del programa mediante un estudio de correlación (coeficiente $r$ de Pearson) entre el número de especímenes recolectados con variables como la población y el volumen de producción de carne en canal de los municipios visitados. Posteriormente, se calculó el porcentaje de muestras contaminadas de acuerdo a la Jurisdicción Sanitaria (JS) de procedencia y el año de estudio; se elaboraron gráficas que relacionaron los porcentajes anuales de muestras contaminadas en Guerrero versus los obtenidos a nivel nacional, así como con el número de personas intoxicadas durante el periodo estudiado. Los resultados calculados para las JS y los municipios se representaron en mapas temáticos. Estos análisis y gráficos fueron realizados con los programas SPSS versión 21 (IBM Corporation, Estados Unidos de América) y ArcGIS versión 9.3 (ESRI, Estados Unidos de América).

En el análisis de resultados se encontró que la recolección de muestras no fue uniforme en lo que se refiere a la cantidad, ya que en 2011 se analizaron más productos cárnicos que en 
cualquier otro año $(n=172)$, mientras que para el 2012 y 2013 disminuyeron de manera sustancial a 91 y 105, respectivamente. En el 2014 existió una recuperación de esta variable y tuvo una progresión en el año posterior (Cuadro 1). Este comportamiento puede deberse a que el presupuesto destinado para operar el programa de vigilancia sanitaria es diferente en cada año, y las actividades que se destinan implican gastos, lo que afecta directamente en la planeación de las visitas de verificación a las tiendas de autoservicio, rastros y expendios de carne. Además, la dinámica de aparición de muestras contaminadas con clembuterol provocan un rediseño de las estrategias para obtener mejores resultados que inhiban esta actividad ilegal en la producción pecuaria; esto significa poner énfasis en la vigilancia especialmente en las localidades que han presentado casos positivos, dejando en segundo término aquellas en las que no se ha observado este problema. Mediante la aplicación de este enfoque basado en riesgos se logra una eficacia del programa, y una reducción en la utilización de recursos tanto económicos como humanos.

Cuadro 1: Muestras contaminadas / recolectadas y porcentaje de muestras contaminadas por año (\% anual) y jurisdicción sanitaria (JS)

\begin{tabular}{lccccccc}
\hline & $\mathbf{2 0 1 1}$ & $\mathbf{2 0 1 2}$ & $\mathbf{2 0 1 3}$ & $\mathbf{2 0 1 4}$ & $\mathbf{2 0 1 5}$ & Total & JS (\%) \\
\hline Tierra Caliente & $4 / 25$ & $0 / 9$ & $6 / 26$ & $2 / 24$ & $1 / 23$ & $13 / 107$ & 12.1 \\
Norte & $4 / 22$ & $2 / 12$ & $0 / 10$ & $6 / 19$ & $4 / 30$ & $16 / 95$ & 16.8 \\
Centro & $2 / 36$ & $1 / 8$ & $0 / 19$ & $0 / 21$ & $4 / 32$ & $7 / 116$ & 6.0 \\
Montaña & $0 / 9$ & $2 / 4$ & $0 / 11$ & $0 / 11$ & $1 / 7$ & $3 / 42$ & 7.1 \\
Costa Grande & $4 / 28$ & $1 / 16$ & $0 / 11$ & $0 / 13$ & $0 / 24$ & $5 / 92$ & 5.4 \\
Costa Chica & $0 / 17$ & $0 / 12$ & $0 / 8$ & $5 / 20$ & $0 / 24$ & $5 / 81$ & 6.2 \\
Acapulco & $8 / 35$ & $1 / 30$ & $0 / 18$ & $2 / 21$ & $1 / 21$ & $12 / 125$ & 9.6 \\
& 12.8 & 7.7 & 5.7 & 11.6 & 6.8 & 9.3 & \\
Annual, \% & $\mathrm{n}=172$ & $\mathrm{n}=91$ & $\mathrm{n}=105$ & $\mathrm{n}=129$ & $\mathrm{n}=161$ & $\mathrm{n}=658$ & \\
\hline
\end{tabular}

Con respecto al tipo de muestras, hubo cierta igualdad en la cantidad recolectada tanto de hígado $(n=329)$ como de músculo $(n=310)$ (Cuadro 2). La COFEPRIS a través de la Comisión de Operación Sanitaria establece en su Instrucción de trabajo ${ }^{(14)}$ que en las visitas de verificación sanitaria a los rastros, carnicerías y tiendas de autoservicio deben colectarse los productos cárnicos por triplicado, una muestra para su análisis en el Laboratorio Estatal, otra para resguardo de la Subsecretaría de Regulación Sanitaria y la tercera para el propietario del establecimiento regulado, por si tuviese alguna inconformidad con el resultado, pueda recurrir con base a su derecho, al análisis en otro laboratorio tercero autorizado del país (para que de esa manera se proceda a la emisión de un dictamen definitivo por parte de la autoridad sanitaria correspondiente). 
Cuadro 2: Porcentaje de muestras detectadas con clembuterol por tipo de muestra y año correspondiente

\begin{tabular}{|c|c|c|c|c|c|}
\hline \multirow{2}{*}{ Año } & \multirow{2}{*}{$\begin{array}{c}\text { Tipo de } \\
\text { muestra }\end{array}$} & \multicolumn{2}{|c|}{ Resultado } & \multirow{2}{*}{ Total } & \multirow{2}{*}{$\%$} \\
\hline & & No detectado & Detectado & & \\
\hline \multirow{2}{*}{2011} & Hígado & 89 & 15 & 104 & 16.9 \\
\hline & Músculo & 61 & 7 & 68 & 11.5 \\
\hline \multirow{2}{*}{2012} & Hígado & 53 & 7 & 60 & 13.2 \\
\hline & Músculo & 31 & 0 & 31 & 0 \\
\hline \multirow{3}{*}{2013} & Hígado & 37 & 1 & 38 & 2.7 \\
\hline & Músculo & 56 & 4 & 60 & 7.1 \\
\hline & Globo ocular & 6 & 1 & 7 & 16.7 \\
\hline \multirow{2}{*}{2014} & Hígado & 53 & 4 & 57 & 7.6 \\
\hline & Músculo & 61 & 11 & 72 & 18.0 \\
\hline \multirow{3}{*}{2015} & Hígado & 67 & 3 & 70 & 4.5 \\
\hline & Músculo & 74 & 5 & 79 & 6.8 \\
\hline & Orina & 9 & 3 & 12 & 33.3 \\
\hline
\end{tabular}

Entre las regiones, la recolección se llevó a cabo de manera similar con excepción de la Montaña, en la que se obtuvieron solamente 42 muestras (Cuadro 1). Las condiciones de difícil acceso a las localidades pueden ser un factor importante que limite la operación del programa en esta zona del Estado, tomando en cuenta además que el transporte y conservación de las muestras deben realizarse a una temperatura entre 2 y $8^{\circ} \mathrm{C}$, y como los tiempos de traslado hacia el laboratorio suelen ser prolongados, es posible que la red fría se rompa en algún momento perjudicando así la calidad de la muestra, siendo éste otro factor que puede incidir en la escasa recolección observada en esta región. En lo que respecta a los municipios, se visitaron un total de 39 de los 81 que conforman el Estado (48.1\%), concentrándose la atención en aquellos con una mayor población e importancia, tanto turística como económica y política, como son Acapulco $(n=119)$, Chilpancingo $(n=73)$, Iguala ( $n=39)$, Tlapa $(n=31)$, Ciudad Altamirano $(n=34)$ y Zihuatanejo $(n=29)$ (Figura 1). En un análisis de correlación entre el número de habitantes en los municipios visitados y la cantidad de productos cárnicos recolectados en estos, se obtuvo una alta relación entre estas dos variables ( $r=0.912, P<0.001$ ), lo cual es lógico, ya que en la medida que existen más consumidores la vigilancia sanitaria debe aumentarse con la finalidad de prevención y control de riesgos. No existió una relación entre los niveles de producción de carne en canal de los municipios, con las muestras obtenidas en estos $(r=-0.045)$, es decir, la recolección de muestras no se vio influenciada por los altos volúmenes producidos en algunos municipios. Con base a lo anterior, es recomendable ampliar la cobertura del muestreo en los municipios y regiones para tener más posibilidades de detección de casos positivos, y así tener elementos para la toma de decisiones que coadyuven a lograr mejores resultados en la vigilancia sanitaria del clembuterol. 
Figura 1: Recolección de productos cárnicos en los municipios de Guerrero

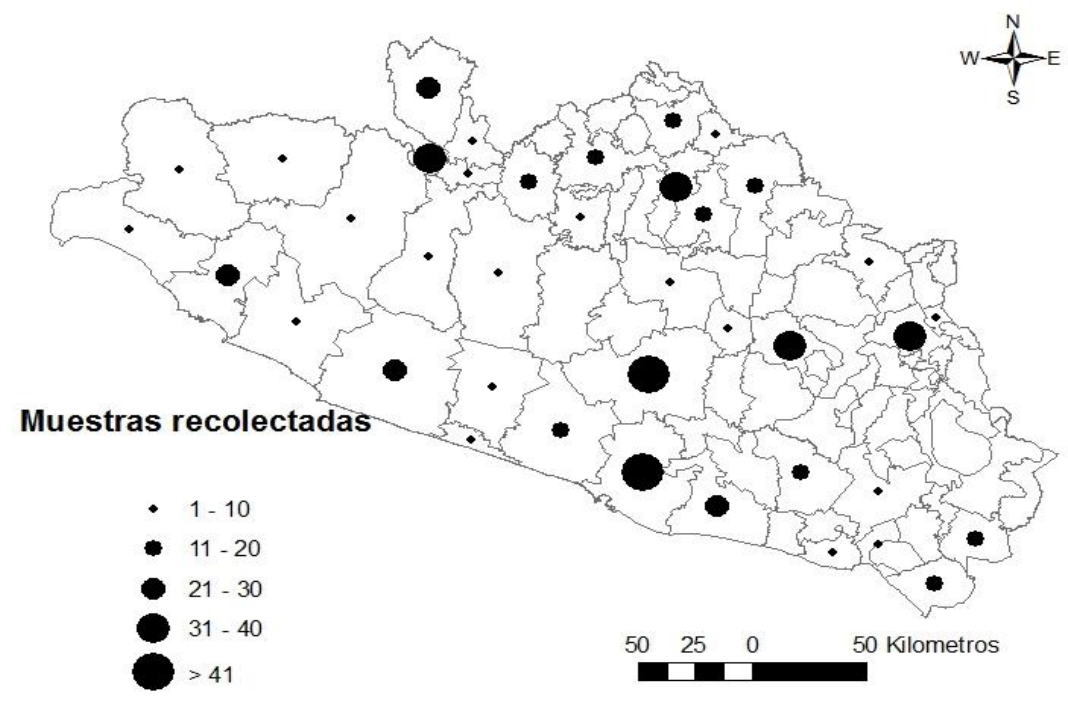

El porcentaje de muestras positivas, es decir, la relación entre la cantidad de productos cárnicos contaminados con clembuterol con respecto al total de los productos cárnicos recolectados, presentó una tendencia a la baja con el transcurso de los años (Cuadro 1). Dicha disminución se presentó de manera gradual, con la excepción del año 2014 en el que se obtuvo un ligero incremento $(11.6 \%)$. Al final, este porcentaje se vio reducido aproximadamente a la mitad de lo que se observó inicialmente $(2011=12.8 \%$ vs 2015=6.8 $\%)$. Lo anterior indica un logro importante del programa de vigilancia del clembuterol en la reducción de riesgos sanitarios para los consumidores de carne de ganado bovino de esta entidad federativa. El porcentaje global $(9.3 \%)$ fue menor a lo obtenido por Chávez et al ${ }^{(15)}$ en un estudio similar correspondiente a los años 2005-2010, cuyo porcentaje anual promedio fue de $13.1 \%$, con valores en 2005 de hasta casi $24 \%$ de muestras contaminadas con este agente químico. No obstante, estas cifras siempre estuvieron por encima de lo obtenido a nivel nacional (media Guerrero $=9.5 \%$, media Nacional $=5.8 \% ; P=0.1$ ) (Figura 2), y en algunos casos como en el 2011, el porcentaje de muestras positivas en Guerrero fue el doble con respecto al resto del país (12.8 vs $5.1 \%$ respectivamente), por lo que debe plantearse una meta de revertir este comportamiento en el mediano o corto plazo para tener niveles de contaminación más acordes a la realidad nacional en torno a este problema. 
Figura 2: Comparación de los porcentajes de muestras positivas en Guerrero y a nivel nacional durante 2011-2014

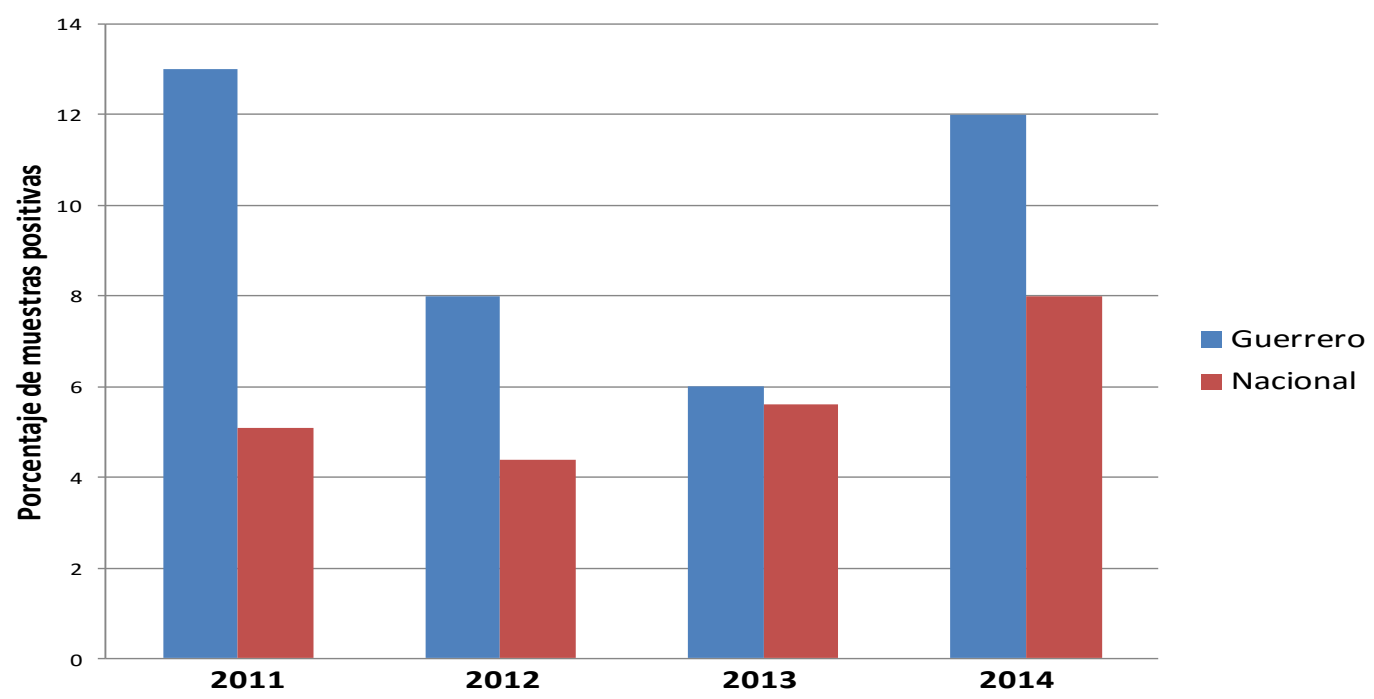

El globo ocular y la orina no fueron las muestras de elección en el esquema de muestreo del programa, sin embargo, como se observa en el Cuadro 1, se tuvo más éxito en la detección de clembuterol en estas muestras biológicas, en las que sólo bastaron siete especímenes de globo ocular para encontrar residuos del fármaco en uno de estos, y del mismo modo, con tan sólo nueve muestras de orina se detectaron hasta tres de ellas con el compuesto de interés. Esto tiene su fundamento en la farmacocinética de la molécula, ya que se han reportado altas concentraciones de clembuterol en retina después de su administración a niveles terapéuticos, y por lo tanto, una alta permanencia ${ }^{(16)}$. De la misma manera, se excreta lentamente a través de la orina y puede encontrarse en los 10 días siguientes a la exposición a este agente ${ }^{(17,18)}$, en tanto que en sangre solamente puede ser detectado durante cinco días posteriores a su ingesta $^{(19)}$. A pesar de la evidencia presentada en éste y otros estudios ${ }^{(16,20)}$, no se ha optado por recolectar muestras de globo ocular por no cumplirse la condición de obtener tres especímenes del mismo animal (por razones lógicas) tal como lo marca la Instrucción de trabajo de la COFEPRIS ${ }^{(14)}$. Asimismo, las muestras de orina únicamente se obtienen en operativos especiales de la autoridad sanitaria en los rastros, siendo esta actividad no muy frecuente, ya que responde a casos particulares en los que existe alguna queja pública o se tienen antecedentes de introducción de carne contaminada en estos establecimientos.

En el análisis regional, las principales JS que contribuyeron con mayores porcentajes de muestras positivas fueron la Norte y Tierra Caliente con 16.8 y $12.1 \%$, respectivamente, cuya presencia de este contaminante químico fue constante en casi todos los años estudiados. En Acapulco, a pesar de la intensa vigilancia realizada (fue el sitio en el que se recolectaron más muestras que en cualquier otra JS) también presentó casos positivos de manera reiterada, aunque en un menor grado que las jurisdicciones mencionadas, con 9.6\%. En las JS restantes, la situación se encontró más controlada y con aparición de casos positivos de manera 
esporádica. Se detectó el clembuterol en 22 municipios, entre los que se destacan aquellos que tienen una mayor población como Acapulco, Chilpancingo, Iguala, Ciudad Altamirano y Tlapa, y es justamente en estos donde se encontraron más casos de muestras contaminadas (Figura 3).

Figura 3: Presencia de clembuterol en los municipios de Guerrero

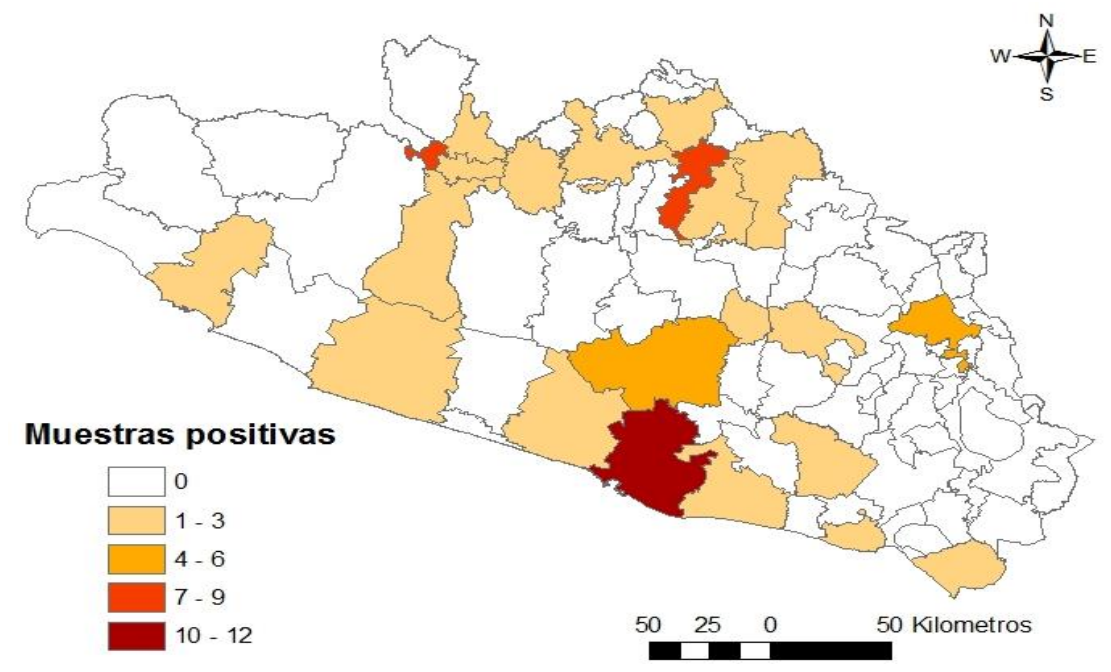

Se registraron algunos casos de intoxicaciones humanas por el consumo de productos cárnicos contaminados con clembuterol, con tres en 2011, cinco en 2012 y cuatro al año siguiente, mientras que para los demás años no ocurrieron eventos de esta naturaleza (Figura 4). De estos casos se registraron seis en Acapulco, tres en Iguala, dos en Chilpancingo y uno en Chilapa, municipios en los que, como se mencionó, se han detectado la mayor cantidad de muestras positivas, con excepción de Chilapa que sólo presentó una muestra positiva, la cual estuvo directamente relacionada con una intoxicación suscitada en 2012. Como en muchos de los padecimientos de salud en México y otros países, hay un sub-registro de las intoxicaciones alimentarias por clembuterol debido posiblemente a una falta de información en el primer nivel de atención para reconocer la sintomatología que implique un estudio más profundo de los casos para llegar a un adecuado diagnóstico ${ }^{(21)}$, a lo que se suma el hecho de que las personas no acuden a los centros de salud para recibir algún tipo de tratamiento, ya sea por falta de recursos económicos o por la escasa oferta de servicios médicos institucionales, por lo que se estima que la cantidad real de estos casos es de una mayor magnitud. 
Figura 4: Porcentaje de muestras contaminadas (barras) y casos de intoxicaciones (línea punteada) en cada año estudiado

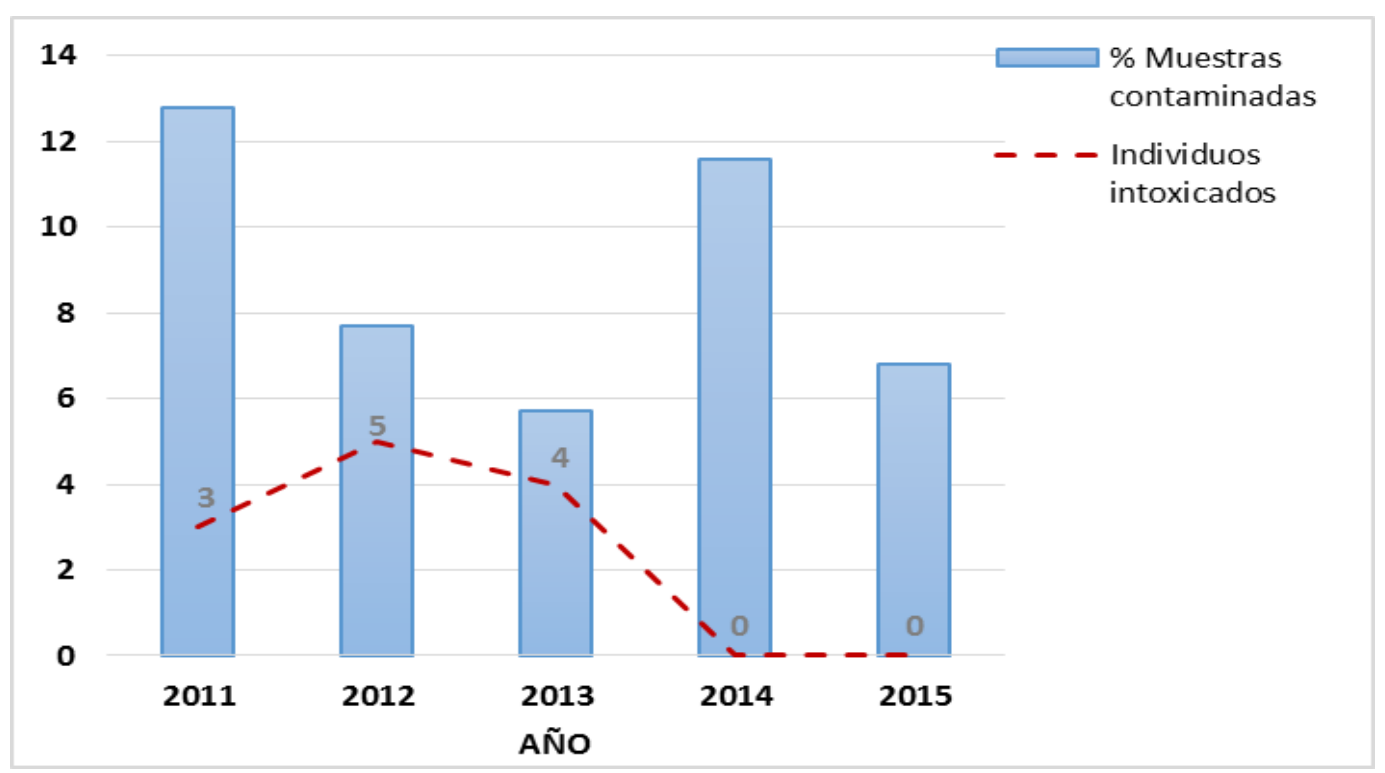

En virtud de que aún existe la presencia de este contaminante químico en los alimentos, es importante mantener y fortalecer el monitoreo mediante la ampliación de las visitas a los establecimientos, así como dar seguimiento a los casos de muestras contaminadas mediante la cadena de trazabilidad para ubicar a los productores de ganado y sensibilizarlos sobre las consecuencias negativas para la salud humana de estas prácticas inadecuadas de producción pecuaria.

Por último, es indispensable la coordinación intersectorial para combatir este problema; cada institución desde el ámbito de sus atribuciones y responsabilidades debe diseñar un esquema integral para la procuración de buenas prácticas de producción desde sus etapas iniciales, que inhiba las intenciones de los ganaderos de obtener mejores rendimientos a costa de la utilización de sustancias peligrosas para el consumidor. Del mismo modo, cuando exista evidencia suficiente sobre el uso ilegal del clembuterol, deben ejecutarse actos de autoridad con base a la legislación vigente y llegar hasta las últimas consecuencias, partiendo del hecho de que esta actividad supone un atentado contra la salud pública, y en ese tenor debe ser sancionada sin reserva ni excepción alguna.

A la luz de estos resultados, y en comparación con años anteriores, es justo mencionar el trabajo que ha realizado la Secretaría de Salud de Guerrero en torno a este fenómeno, con una disminución sustancial de los casos positivos, dando como consecuencia un número menor de intoxicaciones alimentarias. No obstante, debe mantenerse constante la operación del programa de vigilancia para tener como objetivo siguiente erradicar el uso ilegal de clembuterol para proteger a la población contra los riesgos sanitarios relacionados. 


\section{Agradecimientos}

Al personal de la Subsecretaría de Regulación, Control y Fomento Sanitario por la operación del programa de vigilancia sanitaria del clembuterol en Guerrero. A los colegas Roberto Huante y Diego Morán por la asistencia técnica prestada. Al Dr. Hugo Saldarriaga por la revisión del manuscrito y valiosas aportaciones.

\section{Literatura citada:}

1. Sillence MN, Mathews ML, Badran TW, Pegg GG. Effects of clenbuterol on growth in underfed cattle. Austr J Agric Res 2000;51:401-406.

2. Sakai N, Sakai M, Mohamad-Haron DE, Yoneda M, Ali-Mohd M. Beta-agonist residues in cattle, chicken and swine livers at the wet market and the environmental impacts of wastewater from livestock farms in Selangor State, Malaysia. Chemosphere 2016;165:183-190.

3. Kearns CF, McKeever KH, Malinowski K, Struck MB, Abe T. Chronic administration of therapeutic levels of clenbuterol acts as a repartitioning agent. J Appl Physiol 2001;91:2064-2070.

4. Peters AR. b-agonists as repartitioning agents: a review. Vet Rec 1989;124:417-420.

5. Mitchell GA, Dunnavan G. Illegal use of $\beta$-adrenergic agonists in the United States. J Anim Sci 1998;76:208-211.

6. Brett J, Dawson AH, Brown JA. Clenbuterol toxicity: a NSW poisons information centre experience. Med J Aust 2014;200(4):219-221.

7. Hoey AJ, Matthews ML, Badran TW, Peg GG, Sillence MN. Cardiovascular effects of clenbuterol are $\beta_{2}$-adrenoreceptor-mediated in steers. J Anim Sci 1995;73:1754-1765.

8. Brambilla G, Cenci T, Franconi F, Galarini R, Macri A, Rondoni F, Strozzi M, Loizzo A. Clinical and pharmacological profile in a clenbuterol epidemic poisoning of contaminated beef meat in Italy. Toxicol Lett 2000;114(1-3):47-53. 
9. FAO/WHO Expert Committee on Food Additives. Residues of some veterinary drugs in animals and foods. Monographs prepared by the Fourth Meeting of the Joint FAO/WHO Expert Committee on Food Additives. Geneva. 1992.

10. Hoffman RJ, Hoffman RS, Freyberg CL, Poppenga RH, Nelson LS. Clenbuterol ingestion causing prolonged tachycardia, hypokalemia, and hypophosphatemia with confirmation by quantitative levels. Clin Toxicol 2001;39(4):339-344.

11. Diario Oficial de la Federación. NOM-194-SSA1-2004, Productos y Servicios. Especificaciones sanitarias en los establecimientos dedicados al sacrificio y faenado de animales para abasto, almacenamiento, transporte y expendio. Especificaciones sanitarias de productos. http://www.salud.gob. mx/unidades/cdi/nom/194ssa104.html. Consultado 25 Mar, 2016.

12. R-Biopharm AG. Enzyme immunoassay for the quantitative analysis of Clenbuterol and other $\quad \beta$-agonists. http://www.r-biopharm.com/products/food-feedanalysis/residues/hormones-and-anabolics/clenbuterol/item/ridascreen -clenbuterolfast. Accessed Apr 27, 2015.

13. Instituto Mexicano de Normalización y Certificación. NMX-EC-17025-IMNC-2006 Requisitos generales para la competencia de los laboratorios de ensayo y de calibración. México. 2006.

14. Comisión Federal para la Protección contra Riesgos Sanitarios. Comisión de Operación Sanitaria. Instrucción de trabajo para la vigilancia sanitaria del clembuterol en productos cárnicos. México, DF. Secretaría de Salud. 2008.

15. Chávez LA, Diaz JA, Pérez B, Alarcón MA. Tendencia de 2005 a 2010 de los niveles de clembuterol en muestras de bovinos en Guerrero, México. Rev Mex Cienc Pecu 2012;3(4):449-458.

16. Smith DJ, Paulson GD. Distribution, elimination, and residues of [14C] clenbuterol HCl in Holstein calves. J Anim Sci 1997;75(2):454-461.

17. Harkins JD, Woods WE, Lehner AF, Fisher M, Tobin T. Clenbuterol in the horse: urinary concentrations determined by ELISA and GC/MS after clinical doses. J Vet Pharma Therapeutics 2001;24:7-14.

18. Dave M, Sauer MJ, Fallon RJ. Clenbuterol plasma pharmacokinetics in cattle. Analyst 1998;123:2697-2699.

19. Yang YG, Song LX, Jiang N, Xu XT, Di XH, Zhang M. Pharmacokinetics of ambroxol and clenbuterol tablets in healthy Chinese volunteers. Int $\mathbf{J}$ Clin Exp Med 2015;8(10):18744-18750. 
20. Li L, Tang C, Zhao Q, Zhang K. The potential of various living tissues for monitoring clenbuterol abuse in food-producing Chinese Simmental beef cattle. J Anal Toxicol 2016;40(1):72-77.

21. Wu ML, Deng JF, Chen Y, Chu WL, Hung DZ, Yang CC. Late diagnosis of an outbreak of leanness-enhancing agent-related food poisoning. Am $\mathrm{J}$ Emerg Med 2013;31(10):1501-1503. 